\title{
Antibiotic prescriptions in primary health care in a rural population in Crete, Greece
}

\author{
Nikolaos Kontarakis ${ }^{1 \dagger}$, loanna G Tsiligianni ${ }^{1 *}$, Polyvios Papadokostakis ${ }^{2}$, Evangelia Giannopoulou ${ }^{3}$, \\ Loukas Tsironis ${ }^{4}$, Vasilios Moustakis ${ }^{4}$
}

\begin{abstract}
Background: Antibiotic over-prescribing has generally been considered to be common in Greece, however not much is known about current antibiotic use.

Findings: The aim of this study was to investigate antibiotic prescribing in a well-defined rural population of 159 adults and 99 children over a 12-month period in Crete, Greece. The daily-defined doses (DDD) for 1000 people/ day (DID) were 22.1 and 24.2 for children and adults respectively. The overall DID was 23.4, markedly lower than that previously reported for Greece. The use of penicillins was $49.5 \%$ of DDD in children and $31.7 \%$ in adults. Quinolones represented 2.2\% of the total antibiotics (0\% in children). Prescriptions of antibiotics were more common during the 3-month period from January to March for both children and adults.

Conclusions: The findings of this study confirm the seasonal distribution of antibiotics used and the predominance of prescribing for respiratory tract infections. In the area of the study, antibiotic use seems to be lower than that previously reported for Greece, probably as a result of the recently established net of well-trained primary health physicians.
\end{abstract}

\section{Background}

Antibiotic prescribing in primary care rose steadily during the last decade world-wide, in many European countries [1-7]. Unnecessary antibiotic prescribing remains the cardinal contributing factor to the development of antibiotic resistance $[4,5,7,8]$. Primary health care practitioners have been shown to account for the majority of antibiotic prescribing [3]. To prevent overprescribing, detailed data on antibiotic utilization should be obtained [9-11]. The use of markers such as the daily defined doses of antibiotics (DDD), and the daily defined doses for 1000 people/day (DID) for the estimation of antibiotic use has facilitated the comparison of the findings in various countries [12]. Greece is among the European countries with the highest antibiotic prescribing and resistance to bacteria $[3,4]$. Information is very limited for Crete, the major island of Greece [3,13-17]. The aim of this study was to investigate antibiotic use in primary health care in a region of Crete for a period of

\footnotetext{
* Correspondence: pdkapa@yahoo.gr

† Contributed equally

${ }^{1}$ Agia Barbara Health Care Center, Heraklion, Crete, P.O 70003, Greece

Full list of author information is available at the end of the article
}

12 months as well as to highlight the important role of the family physicians.

\section{Methods}

The rural municipality of Gorgolaini, prefecture of Heraklion, Crete, has a population of 3026 (1543 male, 1483 female). Primary health services consist of two public medical offices with 3 general practitioners. From an initial sample of 2394 permanent residents, a representative cohort of 330 individuals was formed by the method used for systematic samples of municipalities $[18,19]$. Of them, 30 (9\%) denied participation, and $42(12.7 \%)$ were not included due to lack of proper information on medical history and drug prescription. In total, 258 persons participated in the study.

The collection of data for the 12-month period from January 1 through December 31 was performed in February and March of the following year (2005). Individual health and prescription booklets were reviewed for medical visits and prescriptions, and demographic and insurance data were recorded. For each medical visit for an infection, the prescribed medication and dosage of the prescribed medication packages were recorded.

\section{Biomed Central}


Drugs were coded according to the Anatomical Therapeutic Chemical (ATC) classification system and the doses according to the Defined Daily Dose (DDD) system [12]. The diseases were coded according to the World Health Organization-International Classification of Diseases System (WHO-ICD 10). The statistical analysis was performed using the SPSS v.17.0. Chi-square test was used in order to compare study variables. Statistical significance was accepted at the 5\% level.

\section{Ethics}

The scientific committee of the Venizeleion Hospital of Heraklion, Crete approved this study. All patients were willing to participate in the study, and were informed about the scope and the purpose of the study and gave their consent.

\section{Results}

The age distribution of the population of the study was as follows: male, age group 0-18: $21.7 \%$, age group 19-65: $16.2 \%$, age group 65+: 9.6\%; and female age group 0-18: 16.6\%, age group 19-65: 21.3\%, age group $65+14.6 \%$. No significant difference was found between males and females regarding age.

The distribution of diagnoses is depicted in Table 1 . Table 2 indicates the most frequently prescribed drugs, in DDDs and DIDs. The DIDs for children were 22.1 and for adults were 24.2. The use of penicillins (J01C) was $49.5 \%$ of DDDs in children and $31.7 \%$ in adults. The most frequently prescribed antimicrobial drug was amoxicillin-clavulanate (43.4\% of the total DID in children). The total percentage of cephalosporins (J01DA) was $19.3 \%$ of DDDs in children and $29.7 \%$ in adults. Ceplalosporins were the most frequently prescribed antimicrobial agent in adults.

Macrolides represented $27.1 \%$ of the total DDD in children, and $27.7 \%$ of DDD in adults. From the group of macrolides-lincozamides (J01F) in children only clarithromycin was prescribed. In adults clarithromycin,

Table 1 Most common diagnoses in adults and children in the study

\begin{tabular}{llll}
\hline & Infection & Episodes & $\%$ \\
\hline Children & Respiratory & 72 & 82.8 \\
& Skin-soft tissues & 7 & 8 \\
& Tooth abscess & 5 & 5.7 \\
& Gastrointestinal & 2 & 2.3 \\
& Others & 1 & 1.1 \\
\hline Adults & Respiratory & 100 & 71.4 \\
& Skin-soft tissues & 16 & 11.4 \\
& Urinary & 12 & 8.6 \\
& Tooth abscess & 8 & 5.7 \\
& Genital & 4 & 2.9 \\
\hline
\end{tabular}

Table 2 Prescribed antibiotics as DDD and DID, and percentages

\begin{tabular}{|c|c|c|c|c|}
\hline Effective Substance & Frequency & DDD & DID & $\% \mathrm{DDD}$ \\
\hline \multicolumn{5}{|l|}{ Children } \\
\hline \multicolumn{5}{|l|}{ Penicillins J01C } \\
\hline $\begin{array}{l}\text { Phenoxymethyl-penicillin } \\
\text { J01CE02 }\end{array}$ & 1 & 6 & 0.17 & 0.8 \\
\hline - Amoxicillin J01CA04 & 5 & 42 & 1.16 & 5.3 \\
\hline $\begin{array}{l}\text { - Amoxicillin-clavulanate } \\
\text { J01CR02 }\end{array}$ & 28 & 346 & 9.57 & 43.4 \\
\hline Cephalosporins J01DA & 24 & 154 & 4.26 & 19.3 \\
\hline Macrolides J01F & 24 & 216 & 5.98 & 27.1 \\
\hline Sulphonamides QJ01EQ & 1 & 14.4 & 0.4 & 1.8 \\
\hline Antifungals D01 & 2 & 10.5 & 0.29 & 1.3 \\
\hline Antiviral J05A & 1 & 2.5 & 0.07 & 0.3 \\
\hline $\begin{array}{l}\text { Antiprotozoal-anthelminthics (P01- } \\
\text { P02) }\end{array}$ & 1 & 6 & 0.17 & 0.8 \\
\hline Total & 87 & 797 & 22.1 & \\
\hline \multicolumn{5}{|l|}{ Adults } \\
\hline \multicolumn{5}{|l|}{ Penicillins J01C } \\
\hline $\begin{array}{l}\text { - Phenoxymethyl-penicillin } \\
\text { J01CE02 }\end{array}$ & 2 & 12 & 0.21 & 0.9 \\
\hline - Amoxicillin J01CA04 & 12 & 162 & 2.79 & 11.5 \\
\hline $\begin{array}{l}\text { - Amoxicilline-clavunalate } \\
\text { J01CR02 }\end{array}$ & 16 & 272 & 4.68 & 19.3 \\
\hline Cephalosporins J01DA & 43 & 418 & 7.2 & 29.7 \\
\hline Macrolides J01F & 50 & 389 & 6.7 & 27.7 \\
\hline Quinolones J01M & 5 & 55 & 0.95 & 3.9 \\
\hline Imidazoles J01XD & 2 & 15 & 0.26 & 1.1 \\
\hline Sulphonamides QJ01EQ & 3 & 30 & 0.52 & 2.1 \\
\hline Lincozamides J01F & 2 & 8 & 0.14 & 0.6 \\
\hline Antifungals D01 & 5 & 46 & 0.79 & 3.3 \\
\hline Total & 140 & 1407 & 24.2 & \\
\hline
\end{tabular}

$\mathrm{DDD}=$ daily defined doses of antibiotics, DID = daily defined doses of antibiotics for 1000 people/day.

roxithromycin, telithromycin, azithromycin and clindamycin represented $59 \%, 19 \%, 12 \%, 6 \%$, and $4 \%$ respectively of the total DDD of the J01F group. In children penicillins were prescribed more often than in adults ( $21.4 \%$ versus $39.1 \%, \mathrm{p}=0.049)$, but cephalosporins and macrolides were prescribed less often compared to the adults (30.7\% versus $27.6 \%$ and $35.7 \%$ versus $27.6 \%$, respectively).

Antibiotic prescription according to infections is depicted in Table 3 . In respiratory diseases penicillins (J01C) were prescribed in $48.9 \%$ and $33 \%$ of DDDs in children and adults, respectively. In children penicillins were prescribed for respiratory diseases in $48.9 \%$ of DDD and was the most commonly prescribed agent, while cephalosporins were third in rank (20.1\%). In adults amoxicillin-clavulanate accounted for $20.7 \%$ and cephalosporins for $30 \%$. Macrolides for respiratory infections were commonly prescribed $(29 \%$ and $37 \%$ for 
Table 3 DDDs, DIDs and percentages of DDD of antibiotics according to infection

\begin{tabular}{|c|c|c|c|c|c|c|c|}
\hline Infection & Antimicrobial agents & $\%$ children & $\%$ adults & DDD children (\%) & DDD adults (\%) & DID children & DID adults \\
\hline \multirow[t]{4}{*}{ Respiratory } & Penicillins J01C & $37.5 \%$ & $22 \%$ & $344(48.9 \%)$ & $337.5(33 \%)$ & 9.53 & 9.67 \\
\hline & Cephalosporins J01DA & $29.2 \%$ & $30 \%$ & $142(20.1 \%)$ & $306(30 \%)$ & 3.92 & 5.27 \\
\hline & Macrolides, lincozamides J01F & $31.9 \%$ & $48 \%$ & $204(29 \%)$ & $378(37 \%)$ & 5.65 & 6.51 \\
\hline & Sulphonamides J01E & $1.4 \%$ & 0 & $14.4(2 \%)$ & 0 & 0.4 & 0 \\
\hline \multirow[t]{4}{*}{ Urinary } & Penicillins J01C & & $8.3 \%$ & & $24(18 \%)$ & & 0.41 \\
\hline & Cephalosporins J01DA & & $25 \%$ & & $24(18 \%)$ & & 0.41 \\
\hline & Quinolones J01M & & $41.7 \%$ & & $55(41.4 \%)$ & & 0.95 \\
\hline & Sulphonamides J01 & & $25 \%$ & & $30(22.6 \%)$ & & 0.52 \\
\hline \multirow[t]{4}{*}{ Skin-soft tissues } & Penicillins J01C & $42.8 \%$ & $6.3 \%$ & $15.4(52.4 \%)$ & $12(8.3 \%)$ & 0.58 & 0.21 \\
\hline & Cephalosporins J01DA & $28.6 \%$ & $62.5 \%$ & $6.5(19.5 \%)$ & $88(60 \%)$ & 0.18 & 1.52 \\
\hline & Macrolides, lincozamides J01F & & $12.5 \%$ & & $11(7.5 \%)$ & & 0.19 \\
\hline & Other & $28.6 \%$ & $18.7 \%$ & $7.5(25.5 \%)$ & $35.5(24.2 \%)$ & 0.21 & 1.09 \\
\hline Genital & Other & & $100 \%$ & & $25.5(100 \%)$ & & 0.57 \\
\hline \multirow[t]{2}{*}{ Gastrointestinal } & Macrolides, lincozamides J01F & $50 \%$ & & $12(66.7 \%)$ & & 0.33 & \\
\hline & Other & $50 \%$ & & $6(33.3 \%)$ & & 0.17 & \\
\hline \multirow[t]{3}{*}{ Tooth abscess } & Penicillins J01C & $80 \%$ & $75 \%$ & $30(83.3 \%)$ & $72(90 \%)$ & 0.83 & 1.86 \\
\hline & Cephalosporins J01DA & $20 \%$ & & $6(16.7 \%)$ & & 0.17 & \\
\hline & Macrolides, lincozamides J01F & & $25 \%$ & & $8.0(10 \%)$ & & 0.14 \\
\hline Various & Other & $100 \%$ & & 2.5 (100\%) & & 0.07 & \\
\hline
\end{tabular}

children and adults, respectively. Quinolones were only prescribed in $2.2 \%$ of the total antibiotics, but were the most common agent in adult urinary tract infections (41.4\% of the total DDD). Chi-square test showed no differences in (DID) and number of visits between male and female as well as between adults and children $(\rho>0,05)$. In both children and adults, antibiotics were more commonly prescribed during January-FebruaryMarch (39.6\% and $32.2 \%$ of the total year, for children and adults respectively), followed by the last quarter ( $24.2 \%$ and $26.3 \%$ respectively).

\section{Discussion}

In the present study DIDs were lower than that previously recorded for Greece [3]. This could be explained in part by the fact that in the previous decade family practice in rural areas has been provided by uncertified physicians. Further in urban areas there isn't an established net of well-trained primary health physicians. Over the last decade family practice has reached a revolution and general practitioners provide primary health care services in rural areas as in our study. Our findings further confirmed the seasonal fluctuation of prescriptions, the increased use of broad spectrum antibiotics and the predominance of prescriptions for respiratory tract infections $(82.8 \%$ and the $71.4 \%$ in children and adults, respectively). This is in accordance with Goosens et al study that included 32 countries [3]. In adult respiratory infections, penicillins, cephalosporins and macrolides-lincozamides shared almost equal amounts of the total DDDs. In contrast, in children penicillins were more commonly prescribed. Macrolides-lincozamides accounted for $48 \%$ for respiratory infections in adults and $31.9 \%$ in children, considerably higher than the percentages (18\%) reported previously for Greece [20].

The overall DID rate was 23.4. This DID is one of the highest among European Countries, but it should be stressed that it is lower than the proportions given by the ESAC Project Group for Greece [3]. Recently, rural areas in Greece are increasingly being served by physicians specialized in general practice and this may have contributed to more rational antibiotics prescribing.

The assumption although of DDD and DID in children has several limitation problems as DDDs are normally assigned based on use in adults. The Guidelines for ATC classification and DDD assignment [21] state that the medication dose recommendations will be different depending on the age and body weight of the patient. Because of this, the WHO International Working Group for Drug Statistics Methodology has determined that it is impossible to assign pediatric DDDs, and studies that attempt to investigate drug utilization in children cannot use them. They further recommend that the general DDD be used as a measuring instrument for overall comparisons when the pediatric subgroup is difficult to identify. Therefore in our study the expression of the prescribing DDD in children might have as a result a misserpretation as it relates to an average adult weight. It can be concluded that medication use is considered greater than that estimated, as we cannot estimate precisely DDD and DID in children 
(DDD is the assumed average maintenance dose per day for a drug in adults). As our results showed no significant differences between adults and children it could be estimated that in children either there was a higher morbidity or there was an overuse of antibiotics. It probably means that much bigger fractions of children compared to adults were treated with antibiotics. Even although with these limitations on DDD and DID use, an overall estimation of antibiotic prescribing can be concluded.

The use of penicillins in children was satisfactory (49.5\% of DIDs) but not in adults (31.7\%). The overall use of penicillins in our study (38.1 of DDD) was higher than what was previously reported for Greece $(31.1 \%$ and 21\%) by Tzimis et al [14] and Molstad et al [4] respectively. In accordance with previous studies [3-5], the use of phenoxymethylpenicillin accounted for $1.5 \%$ of the total DDD of penicillins in children and $2.7 \%$ in adults. The increased use of wide-spectrum penicillins and particularly of amoxicillin-clavulanate has been also observed in the adjacent rural Anogia Health Centre area [13]. The predominance of broad spectrum agents has been noted in many countries and has been attributed to marketing campaigns, making physicians less sensitive to cost and quality of the prescribed drugs, and the belief that respiratory infections are an indication for antimicrobials [22-24]. All prescribed cephalosporins were of the second generation. No first-generation cephalosporins were prescribed, again a finding suggesting the unjustified overuse of broad-spectrum agents even in simple infections. No third generation cephalosporins were prescribed, mainly due to the stringent instructions for cephalosporin use that has been imposed by the Greek ministry of health since 1997. The observed increase in the use of macrolides may be explained by the availability of newer agents. Macrolides accounted for $32.6 \%$ of the total prescriptions, a percentage that was higher in comparison with other studies such as Molstad et al and Tzimis et al studies $(21.9 \%$ of the total prescriptions and $22.5 \%$ of DDDs, respectively) $[4,14]$. Macrolides were also used very frequently in the Anogeia Health Centre area, a neighboring county of Crete [13].

The previous prescribed overuse of second generation cephalosporines and macrolides is a well known problem worldwide that leads to a Streptococcus pneumoniae resistance resulting in serious not easily treated infections [25]. Use of non recommended, more expensive, broaderspectrum antibiotics is frequent also in other studies [26]. There is growing concern that using second generation cephalosporins and macrolides may lead common pathogens to develop antibiotic resistance to Streptococcus pneumoniae, Steptococcus pyogenes and Haemophilus influenzae $[3,25,27]$. Further antimicrobial resistance of
S. pneumoniae to penicillin at a country level is often due to macrolides and beta-lactam antibiotics [28]. A systematic review and meta-analysis on the effect of antibiotic prescribing in primary care on antimicrobial resistance showed that individuals that were prescribed an antibiotic in primary care for a respiratory or urinary infection developed bacterial resistance to that antibiotic [29]. This increases the bacterial resistance to first line antibiotics, and has as a result an increased use of second line antibiotics in the community [29].

Although quinolones can be prescribed in Greece only under specific indications, their use was not rare in our study (2.2\% of the total antibiotics), mainly for adult urinary tract infections, where quinolones held first position (42\%). Interestingly not a single prescription of quinolones was documented in children. Comparing our findings with those previously reported for Greece [20], a fall in the percentage of sulfonamides and an increase of quinolones was observed.

In our study there was no registration of antiprotozoal medications and only one registration of a vermifuge medicine. This finding, compatible with a previously report for Crete [30], reflects the optimal hygiene level of the area. Regarding the seasonal distribution of the medical visits, the majority of the antibiotics were prescribed during the first quarter of the year. In Goosens et al study [3] the seasonal distribution in 32 European countries had a mean increase $\geq 30 \%$ in Southeastern countries in the first and last quarter of the year, while the mean increase in North countries was less than $25 \%$.

The decrease of DDD, the lack of third generation cephalosporins prescriptions, and the lack of quinolones prescribed in children are indications that proper medical education and restrictions of prescriptions can help to improve antibiotic utilization in countries with high antibiotic use. On the other hand, the increase of prescribed broad-spectrum agents such as second-generation cephalosporins and quinolones stress that much more must be done.

Further this study showed that the primary indication for antibiotic prescribing was respiratory infections, both in adults and children. In Gjelstad et al study in Norway the respiratory infections accounted for the $60 \%$ of general practitioners' antibiotic prescriptions [31]. Findings were similar in our study. In the Gjelstad et al study the antibiotic prescription has been shown to be influenced by various factors including type of infection, type of contact, being a general practitioner specialist, and years since medical exam [31]. In a retrospective cohort study that took place in UK, adults had higher probability of receiving an antibacterial prescription for a respiratory infection visit compared to children [32]. The antibacterial prescribing declined faster for younger patients than for adults after the implication of successful UK 
strategies for eliminating the antimicrobial use of medicines. Over the last several years a decline in antibiotics prescription in children has been reported in England [33] and this has been attributed to the significant reduction in GPs prescriptions. In our study a high antibiotic prescription for respiratory infections in children has been found, showing that further effort is needed to change GPs approach to childhood respiratory infections.

\section{Implications to the Greek health care system}

Today, Greece spends almost $9.7 \%$ of the GDP (Gross Domestic Product) for health expenses and there is much of discussion about the present economical state, and the medication cost in Greece as well as in Europe. Our study findings should be of interest to health policy makers who are in an extremely difficult financial situation at this time, which should generate more attention to the general practitioner/family medicine specialty that now represents only the $2 \%$ of doctors.

\section{Strengths and limitations}

This study has some limitations which should be reported. The study is a prevalence study so it does not give information about its change overtime. It is a small sample study so broad conclusions cannot be drawn. Large multicenter studies are needed in order to eliminate local factors that can influence the results. The study was conducted in only two rural areas of Crete, and therefore could not be representative of every Greek rural community, so the findings of this study could not be generalized for the whole Greek population. The use of over the counter medicines can not be excluded. The fact that we used a retrospective analysis of antibiotics in patients without interview may have as result an underestimation of the total antibiotic use.

Further the attempted comparison between adult and pediatric antibiotic use has several limitations as comorbidity factors were not examined (diabetes, asthma etc) as well as a possibility of misestimating the results as DDDs are not recommended for children. On the other hand this is a real life study and it is among the few published regarding antibiotic use in primary health care in rural areas in Greece.

\section{Conclusions}

In conclusion, although our findings were derived from a rather limited rural population, it suggests that well trained, primary health physicians rationally distribute antibiotics in the community setting. The findings of this study confirm the seasonal distribution of antibiotics use and the predominance of prescribing for respiratory tract infection. The overuse of cephalosporines and macrolides as revealed in our study represent a major issue for the public health as it could be associated with increased antibiotic resistance.

\section{Abbreviations}

ATC: Anatomical Therapeutic Chemical classification system; DDD: dailydefined doses; DID: daily defined doses for 1000 people/day.

\section{Acknowledgements}

We thank Dr. Candida Delgatty for her kind contribution in linguistically checking this manuscript.

\section{Author details}

${ }^{1}$ Agia Barbara Health Care Center, Heraklion, Crete, P.O 70003, Greece. ${ }^{2}$ Archalohori Primary Health Care Center, Heraklion, Crete, P.O 70300, Greece. ${ }^{3}$ University hospital of Heraklion, Heraklion, Crete, P.O 71201, Greece.

${ }^{4}$ Technical University of Crete, Chania, Crete, P.O 73100, Greece.

\section{Authors' contributions}

IT and NK: collected, analyzed the data and prepared the first draft. NK,IT,PP, EG,LT,VM: have all participated in conception and design, and gave relevant comments. All authors have given their final approval of this version to be published.

\section{Competing interests}

The authors declare that they have no competing interests.

Received: 2 June 2010 Accepted: 15 February 2011

Published: 15 February 2011

\section{References}

1. Martin E, Canavan A, Butler R: A decade of caring for drug users entirely within general practice. Br J Gen Pract 1998, 48:1679-1682.

2. Britten N, Brant S, Cairns A, Hall W, Jones I, Salisbury C, Virji A, Herxheimer A: Continued prescribing of inappropriate drugs in general practice. J Clin Pharm Ther 1995, 20:199-205.

3. Goosens H, Ferech M, Vander Stichele R, Elseviers M: Outpatient antibiotic use in Europe and association with ESAC Project Group. Lancet 2005, 365:579-587.

4. Molstad S, Lundborg CS, Karlsson AK, Otto C: Antibiotic prescription rates vary markedly between 13 European Countries. Scand J Infect Dis 2002, 34:366-371.

5. Huchon GK, Gialdroni-Grassi G, Leophonte P, Manresa F, Schaberg T, Woodhead M: Initial antibiotic therapy for lower respiratory tract infection in the community: a European survey. Eur Respir J 1996, 9:1590-1595.

6. Ortqvist A: Antibiotic treatment of community acquired pneumonia in clinical practice: a European perspective. J Antimicrob Chemother 1995, 35:205-212.

7. Editorial: Antimicrobial prescribing in the United States: good news, bad news. Ann Intern Med 2003, 138:605-606.

8. Emmer C, Besser R: Combating antimicrobial resistance: intervention programs to promote appropriate antibiotic use. Infections in Medicine 2002, 19:160-173.

9. Austin DJ, Kristinsson KG, Anderson RM: The relationship between the volume of antimicrobial consumption in human communities and the frequency of resistance. Proc Natl Acad Sci USA 1999, 96:1152-1156.

10. Whitney CG, Farley MM, Hadler J, Harrison LH, Lexau C, Reingold A, Cieslak PR, Pilishvili T, Jackson D, Facklam RR, Jorgensen JH, Schuchat A: Increasing prevalence of multidrug-resistant Streptococcus pneumoniae in the United States. N Engl J Med 2003, 343:1917-1924.

11. Emmer C, Besser R: Combating antimicrobial resistance: intervention programs to promote appropriate antibiotic use. Infections in Medicine 2002, 19:160-173.

12. World Health Organization Collaborating Centre on Drug Statistics Methodology: About ACT/DDD system. Oslo, Norway: WHO Collaborating Centre on Drug Statistics Methodology; 2009 [http://www.whocc.no/ atcddd/], Accessed 14 March 2009.

13. Antonakis N, Xylouri I, Alexandrakis M, Cavoura C, Lionis C: Seeking prescribing patterns in rural Crete: a pharmacoepidemiological study from a primary care area. Rural and Remote Health 2006, 6:488. 
14. Tzimis L, Katsantonis N, Leledaki A, Vasilomanolakis K, Kafatos A: Antibiotics prescription for indigent patients in primary care. J Clin Pharm Ther 1997, 22:227-235.

15. Tzimis L, Katsantonis N, Leledaki A, Vasilomanolakis K, Kafatos A: Prescribed medication and nutrition of social care patients in Crete, Greece. Public Health 1996, 110:361-367.

16. Tzimis $L$, Kafatos A: Drug utilization and nutrition patterns among children from indigent and emigrant families in Crete, Greece. Public Health 2000, 114:393-397.

17. Syrogiannopoulos G, Grivea I, Katopodis G, Geslin P, Jacobs M, Beratis N: Carriage of antibiotic-resistant Streptococcus pneumoniae in Greek infants and toddlers. European J Clin Microb Infect Dis 2000, 19:288-293.

18. [http://statmaster.sdu.dk/courses/st118/module05/index.html], By Jørgen Lauridsen. Assessed June 2010

19. Cochran W: Sampling Techniques. New York; 3 1977, 205-232.

20. Zogas D, Elefteriou N, Zoga B, Elefteriou K, Liakos M: Antimicrobial agents in primary health care. Use and overuse. Primary Health Care 1998, 10:58-67, in Greek.

21. Guidelines for ATC classification and DDD assignment 2010. 2010 [http://www.whocc.no/filearchive/publications/2010guidelines.pdf].

22. Windmeijer F, de Laat E, Douven R, Mot E: Pharmaceutical promotion and GP prescription behaviour. Health Econ 2006, 15:5-18.

23. Deschepper R, Vander Stichele RH, Haaijer-Ruskamp FM: Cross-cultural differences in lay attitudes and utilisation of antibiotics in a Belgian and a Dutch city. Patient Educ Couns 2002, 48:161-9.

24. Hutchinson JM, Jelinski S, Hefferton D, Desaulniers G, Parfrey PS: Role of diagnostic labeling in antibiotic prescription. Can Fam Physician 2001, 47:1217-24.

25. Cizman M: The use and resistance to antibiotics in the community. Int $J$ Antimicrob Agents 2003, 21:297-30.

26. Linder JA, Stafford RS: Antibiotic treatment of adults with sore throat by community primary care physicians: a national survey, 1989-1999. JAMA 2001, 286:1181-1186.

27. Low DE: Antimicrobial drug use and resistance among respiratory pathogens in the community. Clin Infect Dis 2001, 33(Suppl 3):S206-13.

28. Bronzwaer S, Cars O, Buchholz U, Molstad S, Goettsch W, Veldhuijzen I, Kool J, Sprenger M, Degener J, EARSS participants: A European Study on the Relationship between Antimicrobial Use and Antimicrobial Resistance. Emerg Inf Dis 2002, 8(3):278-82.

29. Costelloe C, Metcalfe C, Lovering A, Mant D, Hay AD: Effect of antibiotic prescribing in primary care on antimicrobial resistance in individual patients: systematic review and meta-analysis. BMJ 2010, 340:c2096, 18.

30. Antonakis N, Tsakountakis N, Tsoulou S, Philipaki M, Lionis C: Drug prescribing in Primary Health Care. The antimicrobials. Archives of Hellenic Medicine 2000, 17:44-51, in Greek.

31. Gjelstad S, Dalen I, Lindbaek M: GPs' antibiotic prescription patterns for respiratory tract infections-still room for improvement. Scand J Prim Health Care 2009, 27(4):208-15.

32. Meropol SB, Chen Z, Metlay JP: Reduced antibiotic prescribing for acute respiratory infections in adults and children. Br J Gen Pract 2009, 59(567): e321-8.

33. Sharland M, Kendall H, Yeates D, Randall A, Hughes G, Glasziou P, Mant D: Antibiotic prescribing in general practice and hospital admissions for peritonsillar abscess, mastoiditis, and rheumatic fever in children: time trend analysis. BMJ 2005, 331(7512):328-9.

\section{Submit your next manuscript to BioMed Central and take full advantage of:}

- Convenient online submission

- Thorough peer review

- No space constraints or color figure charges

- Immediate publication on acceptance

- Inclusion in PubMed, CAS, Scopus and Google Scholar

- Research which is freely available for redistribution

Submit your manuscript at www.biomedcentral.com/submit
Biomed Central 